\title{
VAGOTOMY
}

\section{The Present Position}

\author{
By H. Daintree Johnson, M.B., F.R.C.S. \\ Honorary Assistant Surgeon, Royal Free Hospital; Assistant Lecturer in Surgery, Post Graduate Medical Scho of \\ London
}

The operation of vagotomy was suggested as long ago as 1812 by Brodie and was tried in cases of gastric crises by Exner and Schwatzman in 1912, and Latarjet in 1923. Bircher (1920), Steirlin (1920) and Schiassi (1925) reported good results in peptic ulcer, but the results do not appear to have been lasting and others who tried the operation were soon disappointed. Not until I 942 was really complete interruption of all vagal fibres entering the abdomen attempted, and it is now realized that only if the division is complete are the results lasting.

Dragstedt, who was the pioneer of the complete operation, and who has performed 350 vagotomies, states that the results, even after nearly five years, continue to be so satisfactory that the operation has replaced all other procedures for peptic ulcer in his clinic (Dragstedt, personal communications).

Vagotomy is now passing out of the experimental stage and is becoming established on a firm basis. There is no longer any doubt that, provided all vagal fibres are cut, the subsequent history of patients with peptic ulceration is altogether altered. Although the total number of vagal resections on record is now many hundreds, no case of subsequent perforation has been reported among them, and of those established as complete by the insulin test the very great majority have remained completely free from symptoms.

\section{The Insulin Test}

This test was introduced by Hollander (1944) as a means of demonstrating whether or not an operation for vagal resection had been complete. He found that in dogs a gastric pouch continued to secrete acid in response to insulin induced hypoglycaemia so long as even a few vagal fibres running to it were left intact, but ceased to do so when section was complete.

Hollander recommended the giving of $16-20$ units intravenously to the fasting patient, but the author has found this dose to produce excessive reaction in some patients and now uses 0.7 units per stone of body weight (0.I units per kilo.). The stomach is emptied at the start of the test and at 20 minute intervals for 80 minutes, the titratable acidity being plotted in the usual way. The author has used this test pre-operatively 60 times and has observed no acid response in only six. Three of the patients who gave negative results were tested again, using the same dose of insulin, and each responded normally on the second occasion. In nearly all cases the response to insulin was higher than the response to histamine. In several patients it was as much as twice as high. In eight vagotomized patients submitted to the insulin test repeatedly over periods ranging from four to 18 months, none has yet any return of acid response.

According to Hollander a response may not be obtained unless the blood sugar is depressed below 50 mgms. per cent., and occasionally not even then.

Of the series of 65 vagal resections carried out by Orr and the present author during the past three years, the earlier ones did not achieve a negative insulin test and the the clinical results were variable. Of the last 50, however, in which Orr's improved per-hiatal technique was used, 49 had absence of insulin response after operation. Among these there has since been no single instance of haemorrhage or perforation and no recurrence of pain. All are back on full work and normal diet.

\section{Rationale}

The rationale of vagotomy in peptic ulcer is based upon the belief that the acid factor is para-

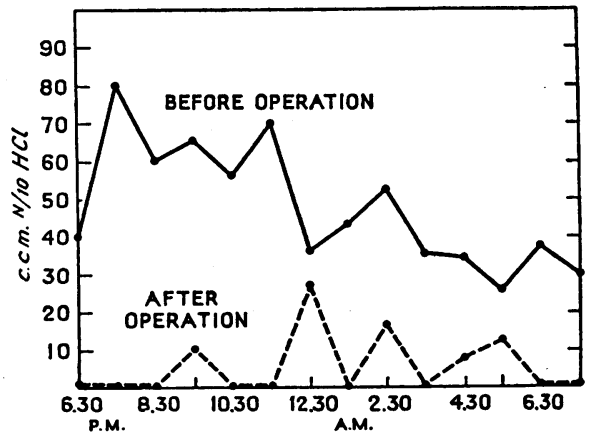

Fig. I.-Free $\mathrm{HCl}$ in hourly samples of spontaneous gastric secretion during sleep, before and fourteen days after vagal resection, in a man aged 35 with twenty years' dyspepsia and proved duodenal ulcer. 
mount in the aetiology and that if this can be controlled, no matter what other factors are at work, no ulceration will occur.

This belief has been greatly strengthened by the work of Mann and Williamson (1923), Wagensteen (et al., 1940) and Shay (et al., 1947).

But a new conception of the mode of action of the acid is evolving which diminishes the importance of acid secreted in response to food and lays the emphasis upon resting secretion. It has been pointed out by Dragstedt and others that the flow of gastric juice which follows the ingestion of food is relatively harmless, for although it contains much titratable acid, it does not cause a high level of $\mathrm{H}$ ion concentration on account of the buffering action of the food itself.

In subjects prone to peptic ulceration an abnormally large volume of resting secretion is often observed and the level of its acidity tends to be high, in duodenal ulcer patients often strikingly so. This secretion is unbuffered by food and, furthermore, in patients with the hypermotile stomachs so typical of duodenal ulcer, it is hurried on into the duodenum before the more slowly produced alkali and buffer containing secretions of the stomach have had time materially to affect its acidity.

Wolf and Wolff (1943) have drawn attention to the considerable effect which emotional states appear to have on the rate of resting secretion.

Vagal resection considerably reduces both the volume and acidity of resting secretion as asserted by Dragstedt and confirmed in our patients (Dragstedt, 1945, Orr and Johnson, 1947), and by several other surgeons (Walters, et al., 1947,
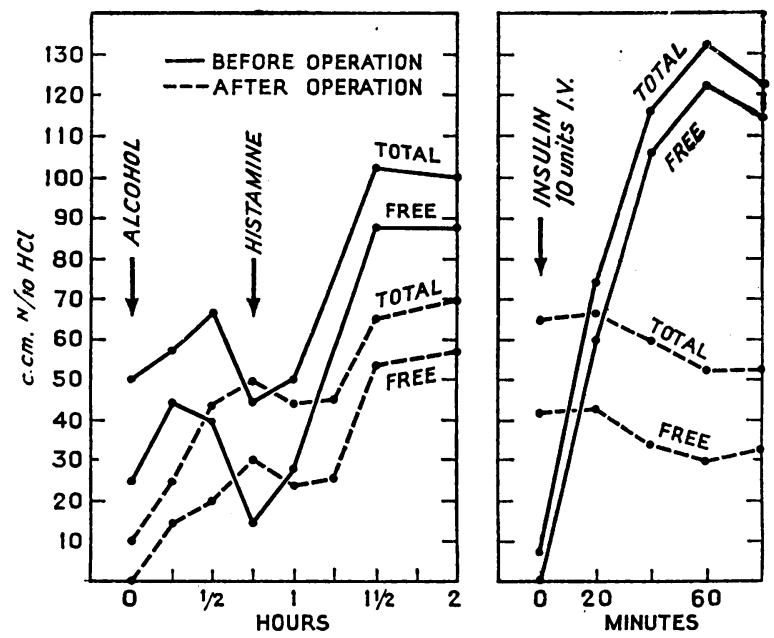

FIG. 2.-Free $\mathrm{HCl}$ and total acid with alcohol, histamine, and insulin test-meals, before and fourteen days after vagal resection, in a man aged 46 with nine years' duodenal ulcer.
Grisvold, 1947, Warren, 1947). There is also good evidence that it breaks the pathway for emotionally conditioned hyper-secretion (Wolf and Andrus, 1947).

Repeating the inconclusive work of Beaver and Mann (1931), Harkins (1947) has demonstrated that vagotomy exercises a remarkable protective effect in preventing the development of ulcers in Main-Williamson dogs. Harkins also found that whereas 17 Control Shay rats all developed ulcers, I 5 rats first vagotomized and then submitted to Shay's procedure developed no ulcers at all.

Vagal section would not be expected to alter the amount of acid produced hormonally in response to the taking of food. However, several workers have attempted to assess the effect of vagotomy by use of the histamine ' test meal,' though this would appear prima facie to be irrational. Furthermore surgeons in describing their results have referred to pre- and post-operative acidity without stating whether this was in response to a test meal or whether it was that of the resting secretion. In order that results may be correlated it is essential that the response to insulin test should be recorded before and after operation and again after an interval of several months. The author also charts the acidity of hourly samples of spontaneous night secretion.

If a histamine test is applied after operation it is,: nevertheless, usual to see a lower curve of acidity than that found before. This is probably at least partly a retention phenomenon due to the delayed gastric emptying time which is an immediate result of vagotomy. Since acid is secreted by the oxyntic cells at a constant strength (Hollander, 1947, Gray, 1947, Davenport, 1947), the titratable acidity of gastric samples is determined mainly by the degree of dilution by other secretions. If not all the resting juice is aspirated before a test meal more dilution occurs, and an apparently lower response is to be expected. After vagal resection it is very difficult completely to empty the stomach owing to the retained food particles and stringy mucus found in it.

Secondly, there appears to be an increased secretion of mucus after vagotomy which would mask the acid by buffering as well as by dilution. After total vagotomy in dogs Vanzant (1947) has shown that the histamine response remains depressed.

Figs. 2 and 5 illutrate histamine and insulin responses before, 14 days after and four months after operation.

Investigation of the spontaneous resting secretion before and after vagotomy shows that the $\mathrm{H}$ ion concentration is consistently and considerably lowered. ' Free $\mathrm{HCl}$ ' becomes, and remains, low 


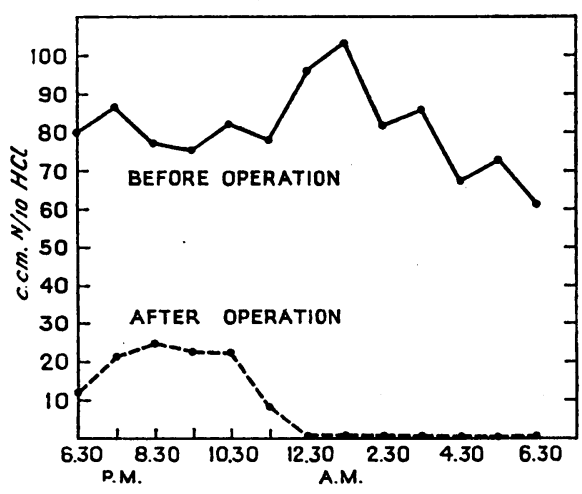

FIG. 3.-Free $\mathrm{HCl}$ in hourly samples of spontaneous gastric secretion during sleep, before and fourteen days after vagal resection combined with gastro-enterostomy, in a man aged 20 with seven years' duodenal ulcer with pyloric stenosis after perforation.

or absent (fig. I). The titratable 'total acid' is sometimes as high as previously and the gap between the curves of 'free $\mathrm{HCl}$ ' and 'total acid' is striking. This indicates a considerable degree of buffering of gastric $\mathrm{HCl}$, what acid there is being retained in the stomach owing to the delay in gastric emptying, but being in a harmless unionized form. As gastric tone returns and the emptying time of the stomach drops to normal, the 'total acid' curve falls to average or low. The titratable ' free $\mathrm{HCl}$ ' remains low. In the course of months there is a tendency for it to become even further reduced, and the volume also continues to decrease.

A possible reason for this is that soon after the vagotomy, when gastric emptying is often greatly delayed, the hormonal effect, due to the persistence of food in the stomach is prolonged. There is no true resting phase as at no time is the stomach completely empty. Only after a few weeks, or even months, when gastric tone has returned to normal, is the true resting secretion observed.

In spite of diligent search no tendency for a return to the former level of resting secretion has been reported or observed by the author after any operation of vagal resection established to have been complete by the insulin test.

Incomplete vagotomy, on the other hand, appears to affect motility more than secretion. At first the acid is lowered owing to the retention of diluents and buffers in the stomach, but as gastric tone returns and the true resting phase is able to be observed, acid secretion is found not to have been reduced as far as it had at first appeared to be.

For the same reason the insulin test should be repeated after an interval of several months, for a negative response just after operation may be due to a failure to aspirate all the large volume of re-
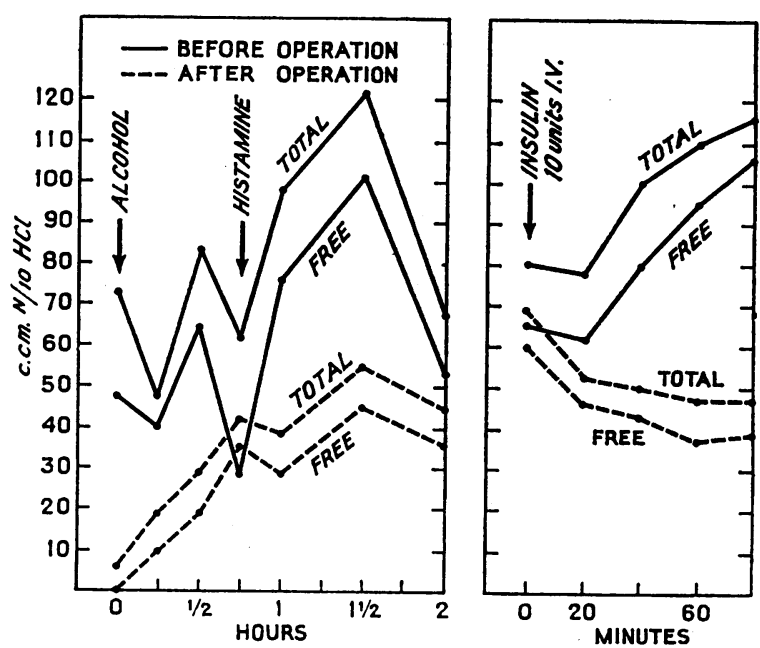

FIG. 4.-Free $\mathrm{HCl}$ and total acid with alcohol, histamine, and insulin test-meals before and fourteen days after vagal resection combined with gastro-enterostomy, in same patient as in Fig. 3 .

tained gastric contents. sometimes present before the test. Vanzant (1947) has reported that no regeneration of the vagus nerves could be detected several years after vagotomy in dogs.

\section{The Relief of Pain}

Patients who were experiencing pain before operation were, in every case, immediately relieved by vagal resection. As the ulcer must require a little while to become healed this phenomenon might suggest that the fibres carrying painful stimuli from the ulcer had been severed. But this is not so, for as has been established experimentally by Grimson (etal., 1947) and others, pain fibres accompany not the vagi but the sympathetic nerves. A case was recorded by Weeks (et al., I946) of death following painless perforation of a peptic ulcer after thoraco-lumbar sympathectomy. Moore (1947) has reported that the introduction of acid into the duodenum continues, for a short while after operation, to cause typical ulcer distress. The author has confirmed this in all of four patients tested.

Whether ulcer distress is due to direct stimulation by acid of nerve endings or whether due to muscle spasm has for long been controversial. Bonney and Pickering (1947) have recently summarized the experimental work of others and added some careful work of their own. Whatever the exact nature of the mechanism there seems to be little doubt that acid in contact with the ulcer is the initiator of the distress and if it is borne in mind that measures calculated to relieve spasm will also prevent the stomach from ejecting its contents into a sensitive duodenum, much of the apparent con- 
tradiction in the experimental results will be resolved.

The author has investigated the spontaneous resting secretion of 16 patients 10 to 14 days after the repair of a perforated duodenal ulcer and has found high levels of acidity, although their ulcer distress had been relieved by operation. He was able to find evidence, however, of reduced gastric motor activity, and believes that the more even gradual evacuation of acid chyme from the stomach is less likely to cause peaks of raised $\mathrm{H}$ ion concentration in the duodenal bulb, with the result that the $\mathrm{pH}$ pain threshold ceases from being surpassed, in the ulcerated area.

\section{The Motor Effect}

Gastric motor activity takes three distinct forms manifested in kymographic study as :-

I. Postural tone. As in other hollow viscera this is fairly constant and largely independent of the degree of distension.

2. Tonus waves. These are seen as gentle regular undulations at a frequency of three per minute and may be peristaltic in nature.

3. Intermittent gastric contractions. These are spastic contractions of the whole stomach which considerably raise intragastric pressure and are present during hunger pains. They occur in bursts at intervals of one and a half to two hours and at a frequency of one every one or two minutes. They appear to be increased in duodenal ulcer patients.

Vagotomy causes an immediate flaccid paresis of the stomach with abolition of all three motor effects. The former two, however, soon return (fig. 6). Hypermotility is not re-established though the emptying time may surn to within normal limits.

It is important to realize that the hyperactive stomach of a duodenal ulcer patient may be effectively compensating a fair degree of pyloric stenosis with the result that the patient may have a normal gastric emptying time. After vagotomy this compensation has been destroyed and the stomach may be no longer able to overcome the obstruction. A moderate degree of stenosis is therefore an indication for combining a gastroenterostomy or a pyloroplasty with the vagotomy. In the series published by Orr and the present author, one in seven were so treated. (The effects of this combined operation on titratable acidity are illustrated in figs. 3 and 4.)

Provided that gastric aspiration is maintained for the first day or two to prevent early overdistension, intrinsic gastric tone returns quickly. Alarming radiological reports of 6,12 or even 24 hour partial retentions may be received and some residue of barium may be seen for days, but seldom
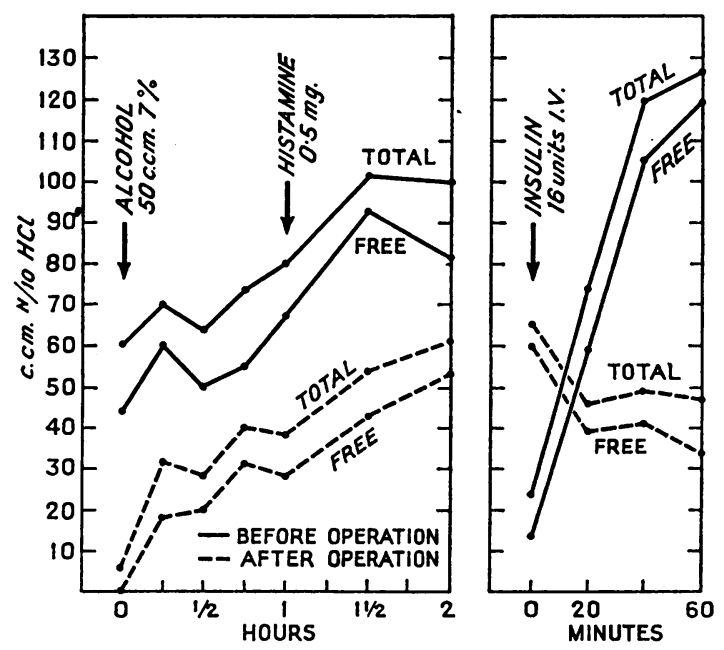

FIG. 5.-Free $\mathrm{HCl}$ and total acid with alcohol, histamine, and insulin test-meals, before and four months after vagal resection, in a man aged $5 \mathrm{I}$ with twelve years' history of duodenal ulcer, showing no recovery of response to insulin.

are there any symptoms, and if the evacuation of fluids is investigated by dye methods it is found that the heavy barium meal is not giving a true index of gastric evacuation. Emptying time is usually restored to normal within a few weeks, though on occasion this has taken several months. Gastric motility can be restored to any required degree at any time, according to Machella (et al., 1947) by the use of urethane of B methyl choline. Nevertheless, it must be borne in mind that vagal resection may bring to light an unsuspected pyloric stenosis for which a short circuit operation will have to be undertaken sooner or later.

\section{Other Effects}

In patients who have suffered from constipation, a common complication of chronic peptic ulcer, there is invariable relief after vagotomy. A single daily bowel action is usual, but transient diarrhoea sometimes occurs (four in the series of 65 previously mentioned). One or two cases have been reported in America in which this symptom persisted, but in our experience it settled within three weeks. It is hard to explain physiologically and is considered more likely to be due to the change in nature of the bowel contents rather than to any motor effect on the bowel itself. Nonetheless the mechanism is being investigated in the remote hope that when elucidated it may prove applicable to Hirschsprung's disease.

It has been suggested that vagotomy is contraindicated in the presence of hypertension and the death of one hypertensive was recorded by Moore et al., 1947) nine months after this operation. The 
author has observed slight rises of blood pressure after vagotomy in one or two patients, but has not yet collected adequate control material to allow assessment of the phenomenon. Electrocardiographs made during manipulation of the nerves have not yet shown any effect.

\section{The Operation}

The earlier attempts at vagal resection were all incomplete operations in which branches of the vagi were cut as they spread out over the cardia. More recent work has shown that these were doomed to failure for to be permanently effective the division must be of the whole of both vagi.

The old text-book descriptions of the vagi are quite inadequate and inaccurate. The complicated nature of actual arrangement has been described by Mitchell (1938 and 1940), Chamberlain and Winship (1947), Bradley (et al., 1947) and others. So difficult was it found to perform a really complete resection from below the diaphragm that most American operators, including Dragstedt and Moore, turned to the trans-thoracic approach. The nerves are easier to see and to cut in the thorax but are just as variable and plural as they are below the diaphragm. The position in which they are most consistently resolved into the fewest number of trunks is actually in the oesophageal hiatus, and it is at that point that Orr (followed by the author) prefers to divide them. They are reached in this position by mobilization of the oesophagus from below.

The abdominal approach has a number of advantages over the thoracic one, not the least being the smoother and less painful post-operative course ; another being that a proper investigation of the ulcer can be made, and any treatment needed to forestall incipient pyloric stenosis undertaken at the same time. Dragstedt, and many other American surgeons, have now abandoned the thoracic approach and returned to per-hiatal resection from below.

The several nerve trunks are easier to feel than to see. The main posterior trunk is the largest in most cases, but is the easiest to miss for it is found, not always on the oesophagus like the anterior branches, but sometimes separate from it, occasionally hidden in the loose connective tissue behind it.

The operation of per-hiatal vagai resection from below is carried out at a considerable depth in a position most difficult of access. Specially designed, illuminated retractors and skilled assistance are almost essential to success. Failure to cut all the fibres of the vagi may be revealed by a positive insulin test after operation, or one which becomes positive in the course of the next few months, though a single negative insulin response is sometimes found pre-operatively, and is, therefore, at no time conclusive evidence of complete vagal section.

\section{Indications for Vagal Resection}

The young patient with a relapsing duodenal ulcer is the one in whom vagal resection is most clearly indicated. A copious and highly acid night secretion (say over $0.5 \mathrm{gms}$. of $\mathrm{HCl}$ in the whole of the 12 hours continuous aspiration) is a reinforcing

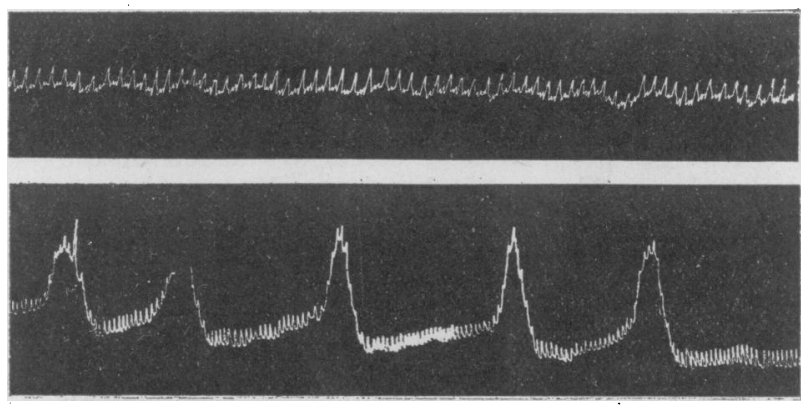

FIG. 6.-Kymograph tracing showing changes in intragastric pressure in a man aged $5 \mathrm{I}$ with twenty years' history of duodenal ulcer. Lower tracing, before operation, shows (I) respiratory effect (frequent small wave at 20 per min.), (2) tonus waves (just discernible undulations at 3 per min., probably peristaltic), and (3) intermittent spasms of the whole stomach (tallest peaks-occurring at $\mathrm{I-2}$ min. intervals). Upper tracing was made after vagal resection and shows absence of gastric spasms. Record was continued for two hours. Before operation, gastric spasms were quiescent for periods of only a few minutes during the hour of observation.

indication. It has been suggested that a high response to insulin indicates 'vagotonia.' It would seem, however, that in peptic ulceration, hyperactivity of the vagus is more likely to be at fault than an excessive gastric response to each vagal stimulus, and it would not seem rational to make deductions from the degree of response to insulin until more experience with this test has accumulated.

It has been recommended by Professor Aird (personal communications) that before advocating vagotomy in patients of late middle age, it should be remembered that we are not as yet in a position to promise more than a four-or five-year cure with this operation, and by employing it in a patient in his fifties we may be delaying a gastrectomy until his sixties and risking complications which in patients of this age are often fatal. Professor Aird maintains that for the present it is wiser to perform gastrectomy in those first coming to operation for duodenal ulcer after fifty.

In old patients, however, in whom the risks of gastrectomy are formidable and whose chance of 
surviving long enough to run any risk of relapse is less, it would seem reasonable to carry out vagotomy to relieve the distress of an intractible ulcer.

Gastric ulcer being predominantly a disease of hypomotile, flaccid stomachs with no gross abnor-mality of secretion, it is surprising that it has responded to vagal resection. Nevertheless, several of the published series have included one or two gastric ulcers some of which appear to have benefited. The increased secretion of mucus is perhaps one of the curative factors. Beazell and Ivy (1936) observed gastric ulcers to occur in rabbits after vagotomy and the author believes hypomotility to be the main aetiological factor in the larger proportion of ulcers to the left of the angulus. The rationale of vagotomy in gastric ulcer does not appear to be on so sound a basis as in duodenal and jejunal ulcers, and most surgeons advise against the use of vagotomy in gastric ulcer.

It may well be that gastric ulcer will prove to be one of the late complications of vagotomy in man.

If the operation should ever come into use for this lesion it will become essential to employ biopsy of the ulcer as an adjunct, even though a gastroscopist may have reported a simple ulcer, or else many early carcinomata are sure to be missed.

In gastro-jejunal and other anastomotic ulcers, which have formed in the past such a recalcitrant problem, the results of vagotomy have proved brilliant indeed, and A. W. Allen, President of the American College of Surgeons, stated in his recent Moynihan lecture in London that he now regards vagal resection as the operation of choice in this condition.

Anastomotic ulcers are almost exclusively a complication of operations performed for duodenal ulcer. Considering, then, the problem of intractable or persistently recurrent duodenal ulcer, we may perform gastrectomy and reserve vagotomy for those that relapse, or we may try vagotomy first and hold gastrectomy in reserve.

In determining which course to choose we must consider not only which operation is most likely permanently to cure the condition, but also which is less likely to affect the patient adversely in other ways and which subjects him to the least danger.

It is almost certainly true that vagotomy will continue to be a safer operation than gastrectomy and though neither operation is without morbidity the advantage seems to be with vagotomy, as far as our present experience goes.

It may be that some such compromise as a combination of vagotomy with a low conservative gastrectomy, aimed rather at the removal of the source of Edkin's factor than at the oxyntic cells, may ultimately prove better than either gastrectomy or vagotomy alone.

Though final assessment will not be possible for many years, it would seem that vagal resection is likely to remain a valuable manoeuvre in the surgical attack on peptic ulcer, though at the best it is but one more step forward in the surgery of this disease. As its limitations become clearer, so will its indications be more exactly defined.

In the words of Orr, who is the foremost exponent of this operation in Britain, 'A lasting success by vagal resection is a triumph of physiological strategy, and a failure spells disappointment but not disaster.'

\section{BIBLIOGRAPHY}

BEAVER, M. C., MANN, F. C. (1931), Ann. Surg., 94, 1116. BEAZELL, J. M., IVY, A. C. (1936), Arch. Path., 22, 213. BONNEY, G. L. W., PICKERING, G. W. (1946), Clin. Sci, , 6, 63 BRADLEY, W. F., SMALL, J. T., WILSON, J. W., WALTERS

W. (1947), ₹. Amer. Med. Ass., 133, 459.

BIRCHER, E. (1920), Schweiz. med. Wchnschr., 25, 519.

CHAMBERLIN, T. A., WINSHIP, T. (1947), Surgery, 2220.

CRILE, G., Jun. (1947), Cleveland Clin. Quart., 14, 65.

DAVENPORT, H. W. (1947), Gastroenterol, 1, 383.

DRAGSTEDT, L. R. (1945), Ann. Surg., 122, 973.

DRAGSTEDT, L. R. (1946), Surg. Gynec. Obstet., 83, 547.

DRAGSTEDT, L. R. (1947), Canad. Med. Ass. F., 56, 133.

DRAGSTEDT, L. R., PALMER, W. L., SCHAFER, P. W., HODGES, P. C. (1944), Gastroenterol, 3, 45.

DRAGSTEDT, L. R., SCHAFER, P. W. (1945), Surgery, 17, 742.

EXNER, A., SCHWARTZMANN, E. (1912), Wein. Klin. Wschr., 25, 1405 .

GRAY (1947), Gastroenterol, 1, 390.

GRIMSON, K. S., HESSER, F. H., KITCHIN, W. W. (1947), Surgery, 22, 230.

GRISVOLD, R. A. (1947), Ann. Surg., 126, 15.

HARKINS, H., HOOKER, D. H. (1947), Surgery, 22, 239.

HOLLANDER, F. (1944), Gastroenterol, 3, 467.

HOLLANDER, F. (1946), Ibid., 7, 607 .

HOLLANDER, F. (1947), Ibid., 1, 401.

LATARJET, M. A. (1921), Bull. Acad. Med. Paris., 87, 68r.

MACHELLA, T. E., HODGES, H. H., LORBER, S. H. (1947), Gastroenterol, 8, 36.

MANN, F. C., WILLIAMSON, C. S. (1923), Ann. Surg., 77, 409.

MITCHELL, G. A. G. (1938), Brit. F. Surg., 26, 333.

MITCHELL, G. A. G. (1940), F. Anat. Lond., 75, 50.

MOORE, F. D. CHAPMAN, W. P., SCHULZ, M. D., JONES, C. M. (1946), New Engl. F. Med., 234, 241.

MOORE, F. D. (1947), F. Amer. Med. Ass., 133, 74 I.

ORR, I. M. JOHNSON, H. D. (1947), Lancet, ii, 84.

RUFFIN, J. M., GRIMSON, K. S., SMITH, R. C. (1946), Gastroenterol, $7,599$.

SANDERS, R. L. (1947), Ann. Surg., 126, 14.

SCHIASSI, B. (1925), Ibid., 81, 939.

SHAY, H., KOMEROV, S. A., FELS, S. S., MERANZE, D. GRUNSTEIN, M., SIPLET, H. (1945), Gastroenterol, 5, 43. STEIRLIN, E. (1920), Disch. Z. Chir., $152,358$.

STORER, E. H., DRAGSTEDT, L. R., CLARK (1946), Surgery,

THOMPSON, V. C., JAMES, A. H. (1947), Lancet, $13,44$.

THORNTON, T. F., jun., STORER, E. H., DRAGSTEDT, L. R. (1946), F. Amer. Med. Ass., 130, 764.

VANZANT, F. R. (1947), Gastroenterol, 8, 768.

WALTERS, W., NEIBLING, H. A., BRADLEY, W. F., SMALL, J. T., WILS'ON, J. W. (1947), Ann. Surg., 126, I.

WANGENSTEEN, O. H., VARCO, R. L.. HAY, L., WALPOLE, S., TRACH, B. (1940), Ibid., 112, 626.

WARREN, R. (1947), Surgery, 22, 246.

WEEKS, C., RYAN, B. J., Van HOY, J. M. (1946), f. Amer. Med. Ass., 132, 988 .

WINKELSTEIN, A., BERG, A. A. (1938), Amer. F. Digest. Dis., $5,497$.

WOLF, S., ANDRUS, de W. D. (1947), Gastroenterol, 8, 429.

WOLF, S., WOLFF, H. G. (1944), 'Human Gastric Function' London. 